\title{
Barrett's Esophagus Complicating Scleroderma
}

\author{
Farooq P. Agha ${ }^{1}$ and Lyubica Dabich ${ }^{2}$ \\ Departments of ${ }^{1}$ Radiology and ${ }^{2}$ Internal Medicine, University of Michigan Hospitals, Ann Arbor, Michigan, USA
}

\begin{abstract}
Two patients with scleroderma whose esophageal involvement was associated with longstanding reflux esophagitis were found to also have Barrett's esophagus. Since Barrett's esophagus is a premalignant condition, these patients with scleroderma should be considered at high risk for the development of adenocarcinoma of the esophagus.
\end{abstract}

Key words: Esophagus, progressive systemic sclerosis - Scleroderma - Barrett's esophagus - Esophagus, columnar lined.

Scleroderma is a generalized multisystem disorder of unknown cause characterized by vascular, fibrotic, and inflammatory changes that involve both skin and internal organs. The latter include digital arteries, gastrointestinal tract, lungs, heart, musculoskeletal system, and kidneys. Within the gastrointestinal tract, the esophagus is involved most commonly and $50-80 \%$ of patients may have esophageal involvement at the time of diagnosis [1-5]. There is disruption of normal esophageal peristaltic activity, and the distal esophageal highpressure zone loses its tone and normal response to swallowing. This hypotonia of the lower esophageal sphincter (LES) leads to gastroesophageal reflux, which, coupled with the inability of the dilated lower esophagus to clear refluxed material back into the stomach, creates an ideal setting for development of reflux esophagitis. This, in turn, not infrequently results in stricture formation. Chronic reflux esophagitis may also lead to Barrett's esophagus, or the replacement of the acid-

Address reprint requests to: Farooq P. Agha, M.D., University Hospital, Box 013, Department of Radiology, 1405 East Ann Street, Ann Arbor, MI 48109, USA damaged squamous epithelium with columnar epithelium. Although Barrett's esophagus should be a common complication of scleroderma, it has only been recognized recently $[1,2]$. Of the 5 cases so far reported 3 had adenocarcinoma of the esophagus complicating Barrett's mucosa.

We describe 2 patients with scleroderma whose long-standing history of reflux esophagitis was associated with the development of Barrett's esophagus. The difficulties of diagnosing Barrett's esophagus in patients with scleroderma are discussed.

\section{Case Reports}

\section{Case 1}

The diagnosis of scleroderma was made in a 38 -year-old black woman in 1972 based on a 2-year history of Raynaud's phenomenon and lung and esophageal involvement. Her symptoms of recurrent peptic esophagitis necessitated a Collis--Belsey hiatus hernia repair in 1975 and revision to Collis-Nissen fundoplication in 1978. However, she continued to have gastroesophageal reflux with substernal pain, heartburn, and dysphagia. A barium swallow revealed a dilated atonic esophagus with severely disordered motility and free spontaneous gastroesophageal reflux (Fig. 1). Endoscopy and esophageal function tests confirmed the presence of spontaneous gastroesophageal reflux and severe ulcerative reflux esophagitis. A biopsy specimen of the esophagus revealed the changes of advanced reflux esophagitis. Despite medical antireflux treatment regimen and 2 antireflux operations she was disabled by her esophageal difficulties. No specific radiographic, endoscopic, or histopathologic features suggested Barrett's esophagus.

In October 1979 she underwent transhiatal esophagectomy and cervical esophagogastric anastomosis. The histopathologic examination of the resected esophageal specimen revealed changes of reflux esophagitis and Barrett's mucosa (Fig. 1). Her only postoperative complication was paralysis of the left true vocal cord related to traction injury to the recurrent laryngeal nerve during surgery, which required Teflon ${ }^{\circledR}$ injection. Occasionally she has required dilatation of her cervical esophagogastric anastomosis because of mild cervical dysphagia in the 4 years since surgery. Otherwise she is eating a regular diet and her systemic disease is stable. 

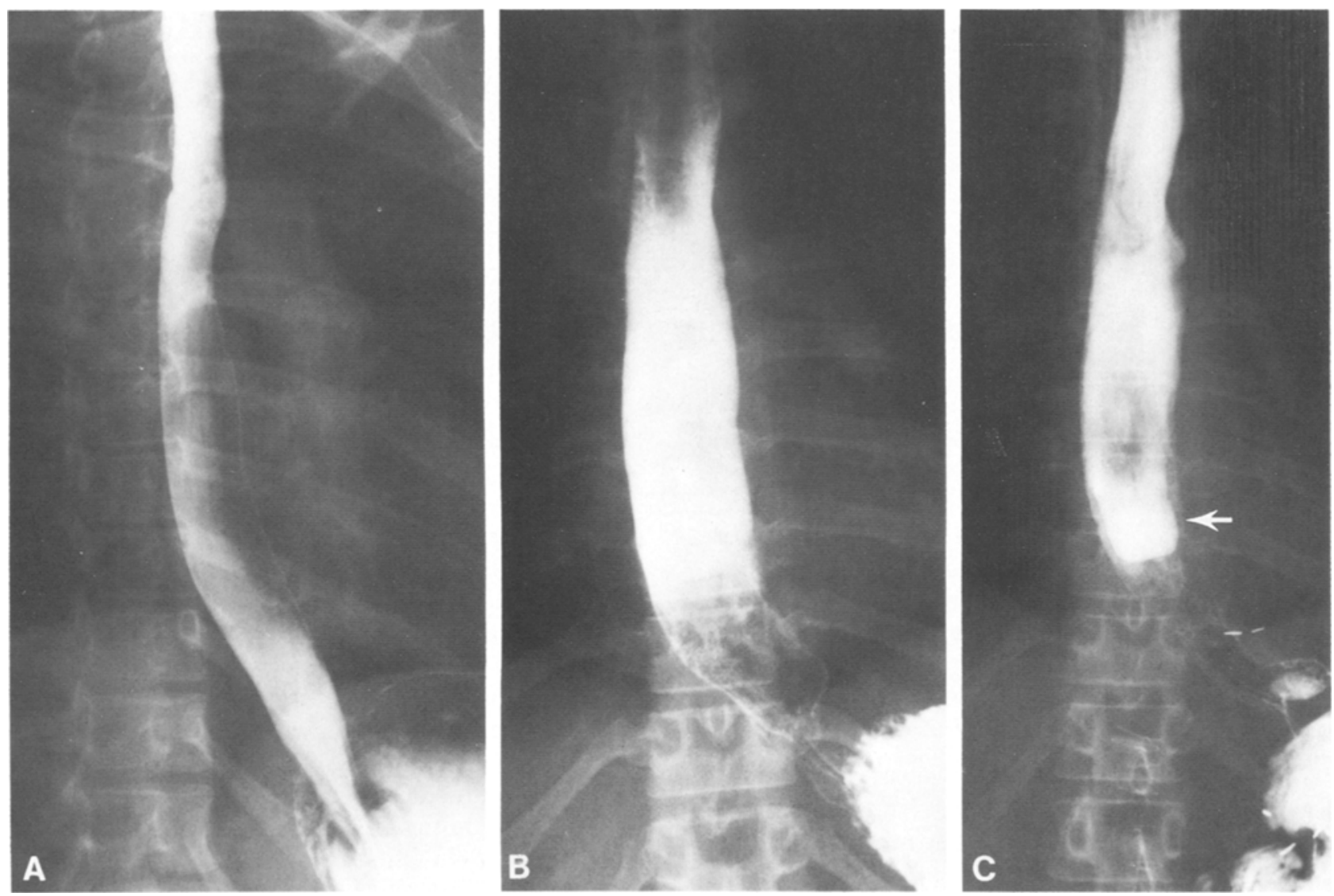

\section{Case 2}

The diagnosis in 1968 of scleroderma in this 44-year-old white women was made based on her history of Raynaud's phenomenon and subcutaneous calcinosis which had to be removed frequently from her fingers and knees. In July 1979 she was referred to University Hospital for evaluation of dysphagia and to rule out the possibility of a malignant tumor of the esophagus. Her history at that time included dysphagia with food sticking in the midesophagus, as well as 15-20 years of substernal burning pain with definite postural aggravation. Intermittently during sleep she also noted regurgitation of acid through her nose and mouth. These symptoms had gradually increased over the previous 5 years. She had been treated with antireflux measures but failed to obtain significant relief.

A barium swallow revealed a dilated atonic esophagus, a small hiatal hernia, a stricture in the distal esophagus, and spontaneous gastroesophageal reflux (Fig. 2). Esophageal function tests confirmed an advanced stage of involvement by scleroderma and severe gastroesophageal reflux. Endoscopy revealed severe ulcerative esophagitis. A biopsy specimen of the distal esophagus failed to show malignancy, but there were changes of reflux esophagitis and the appearance of columnar epithelium was consistent with Barrett's mucosa (Fig. 2). In November 1979 she underwent a Collis-Nissen fundoplication operation. Her postoperative course was unremarkable. She has complained on occasion of minor heartburn in the 4 years since surgery, and is being evaluated yearly with endoscopy and barium esophagography.

\section{Discussion}

For the past 2 decades attention has been focused on both the physiological and radiographic aspects of the esophageal changes in patients with scleroderma [3-11]. The motor disorder ranges from decreased peristaltic waves to complete aperistalsis. Although lower esophageal sphincter hypotonia is generally present, an occasional patient may manifest normal LES pressure. The abnormality was assumed to be the result of fibrous replacement of muscle. However, a combined manometricpathologic study showed defects in peristalsis in the absence of fibrosis or muscular atrophy, which suggested a functional abnormality [12]. Pharmacologic testing was consistent with either a neural or a primary myogenic defect as the cause of LES hypotonia [13]. The main radiologic features of esophageal involvement with scleroderma have been well-documented $[4-6,14,15]$ and consist of a dilated esophagus with decreased peristaltic activity, most commonly in the lower two-thirds, and a wide gastroesophageal junction with incompetent cardia resulting in free and spontaneous gastro- 

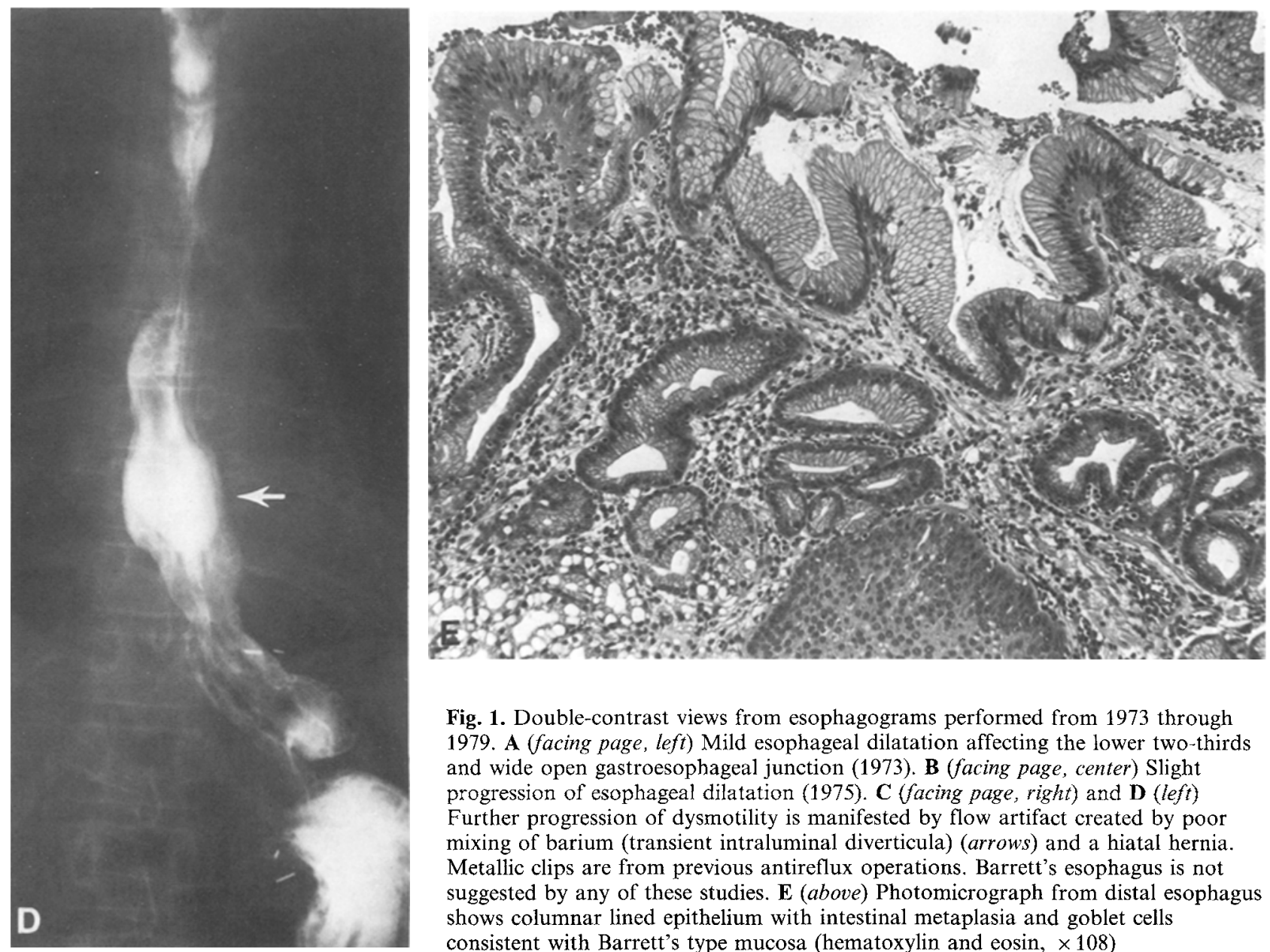

Fig. 1. Double-contrast views from esophagograms performed from 1973 through 1979. A (facing page, left) Mild esophageal dilatation affecting the lower two-thirds and wide open gastroesophageal junction (1973). B (facing page, center) Slight progression of esophageal dilatation (1975). C (facing page, right) and $\mathbf{D}$ (left) Further progression of dysmotility is manifested by flow artifact created by poor mixing of barium (transient intraluminal diverticula) (arrows) and a hiatal hernia. Metallic clips are from previous antireflux operations. Barrett's esophagus is not suggested by any of these studies. $\mathbf{E}$ (above) Photomicrograph from distal esophagus shows columnar lined epithelium with intestinal metaplasia and goblet cells consistent with Barrett's type mucosa (hematoxylin and eosin, $\times 108$ )

esophageal reflux. This leads to reflux esophagitis and may result in stricture formation [16-19]. Less frequently, chronic reflux esophagitis may lead to the development of Barrett's mucosa. Although gastroesophageal reflux is common in patients with scleroderma, Barrett's esophagus was not reported until 1978. Cameron and Payne [1], in a review of Mayo Clinic patients, reported 2 cases of scleroderma complicated by development of Barrett's esophagus. Recently, Halpert et al. [2] reported adenocarcinoma of the esophagus in 3 patients with scleroderma who also demonstrated adjacent areas of Barrett's mucosa. Malignancy in patients with scleroderma is much less common than in those with dermatomyositis. However, several reports described malignant tumors of lung, breast, and, less commonly, esophagus [20-25].

The actual incidence of Barrett's esophagus in patients with scleroderma is difficult to determine. With recent awareness of Barrett's esophagus as a premalignant condition, this diagnosis is probab- ly made more often. We suspect that many cases of Barrett's esophagus in patients with scleroderma were missed because of lack of awareness of this association. Increased awareness of Barrett's esophagus in patients with scleroderma will lead to greater detection of this entity, provided biopsy specimens of the esophagus are obtained for histologic examination. A search of records at the University of Michigan revealed only 2 cases among 502 registered and treated cases of scleroderma between 1975 and 1984. This does not suggest increased incidence. Perhaps more cases of Barrett's esophagus had been missed in this group of patients and the condition is probably more common than reported.

It is important to recognize this association between scleroderma and Barrett's esophagus because of the high frequency of gastroesophageal reflux and reflux esophagitis in these patients. However, several difficulties arise in diagnosing Barrett's mucosa in patients with scleroderma on 


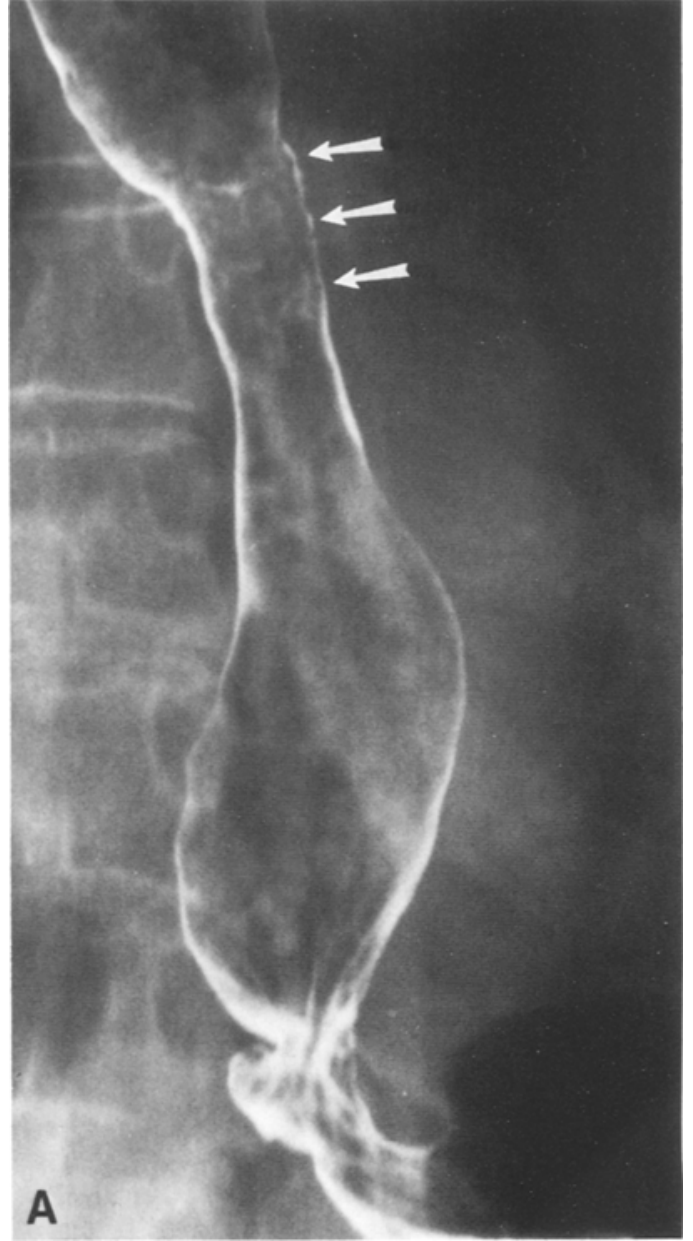

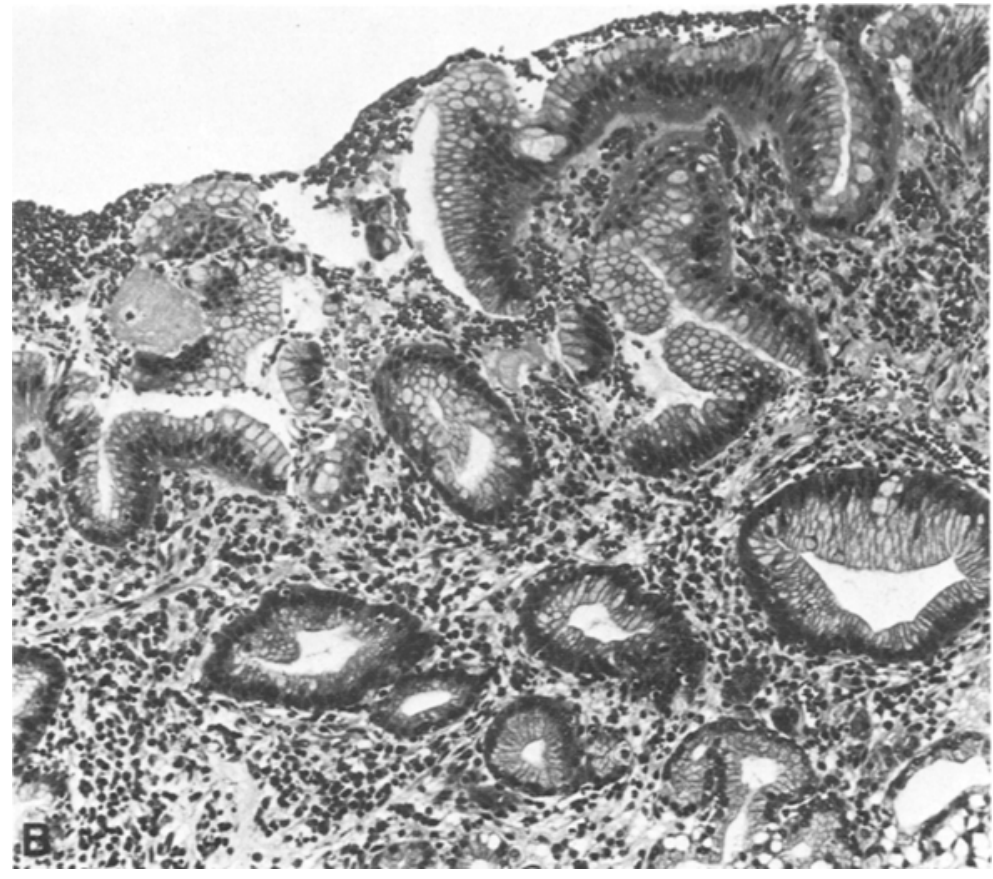

Fig. 2. A A view from double-contrast esophagogram shows a small hiatal hernia and an area of stricture in the distal esophagus not far above the hiatal hernia. The mucosa shows a reticular pattern at the level of the stricture extending distally for a short distance (arrows). This is a retrospective observation; the diagnosis of Barrett's esophagus was not suggested at the time. B Photomicrograph of biopsy specimen from the area of the stricture shows columnar lined epithelium with intestinal metaplasia and goblet cells consistent with Barrett's type mucosa (hematoxylin and eosin, $\times 108$ ) esophagogram. Hiatus hernia, gastroesophageal reflux, dilated esophagus with dysmotility, chronic reflux esophagitis, and strictures are nonspecific features [26]. On double-contrast esophagography, a reticular pattern of the mucosa [27] may be helpful in suggesting the diagnosis of Barrett's mucosa, but it is found in only $12.5-24 \%$ of patients [28]. The endoscopist encounters the same difficulties in diagnosing Barrett's mucosa amid changes of chronic reflux esophagitis and severe degrees of dysmotility. We recommend endoscopic biopsy of esophagus in patients with scleroderma who have persistent gastroesophageal reflux and chronic symptomatic reflux esophagitis. As in our case 1, several biopsy specimens did not show Barrett's mucosa and the diagnosis was made at the histologic study of surgical specimen after esophagectomy.

Since Barrett's esophagus is considered a premalignant condition predisposing to the development of adenocarcinoma [29-35], its recognition in patients with scleroderma is important for iden- tification of this high-risk group so that close follow-up can be instituted.

Acknowledgment. The authors gratefully acknowledge the assistance of Henry D. Appelman, M.D., Professor of Pathology, University of Michigan, for reviewing the histologic material.

\section{References}

1. Cameron AJ, Payne WS: Barrett's esophagus occurring as a complication of scleroderma. Mayo Clin Proc 53:613-615, 1978

2. Halpert RD, Laufer I, Thompson JJ, Feczko PJ : Adenocarcinoma of the esophagus in patients with scleroderma. $A J R$ 140:927-930, 1983

3. Poirier T, Rankin G: Gastrointestinal manifestations of progressive systemic sclerosis based on a review of 364 cases. Am $J$ Gastroenterol 58:30-44, 1972

4. Berk R: The radiology corner: scleroderma of the gastrointestinal tract. Am J Gastroenterol 61:226-231, 1974

5. Olmsted W, Modewell $\mathrm{J}$ : The esophageal and small bowel manifestations of progressive systemic sclerosis. Gastrointest Radiol 1:33-36, 1976

6. Cohen S, Laufer I, Snape WJ Jr, Shiau YF, Levine GM, Jimenez S: The gastrointestinal manifestations of sclero- 
derma: pathogenesis and management. Gastroenterology $79: 155-166,1980$

7. Stevens MB, Hookman P, Siegel CI, Esterly JR, Schulman LE, Hendrix TR: Aperistalsis of the esophagus in patients with connective-tissue disorders and Raynaud's phenomenon. $N$ Engl J Med 270:1218-1222, 1964

8. Saladin TA, French AB, Zarafonetis CJD, Pollard HM: Esophageal motor abnormalities in scleroderma and related disorders. Am J Dig Dis 11:522-535, 1966

9. Atkinson M, Summerling MD: Oesophageal changes in systemic sclerosis. Gut 7:402-408, 1966

10. Garrett JM, Winkelmann RK, Schlegel JF, Code CF: Esophageal deterioration in scleroderma: Mayo Clin Proc 46:92-96, 1971

11. Cohen S, Fisher R, Lipshutz W, Myers A, Schumacher R: The pathogenesis of esophageal dysfunction in scleroderma and Raynaud's disease. $J$ Clin Invest $51: 2663-2668,1972$

12. Treacy WL, Baggenstoss AH, Slocumb CH, Code CF: Scleroderma of the esophagus. A correlation of histologic and physiologic findings. Ann Intern Med 59:351-356, 1963

13. Weihrauch TR, Korting GW, Ewe K, Vogt G: Esophageal dysfunction and its pathogenesis in progressive systemic sclerosis. Klin Wochenschr 56:963-968, 1978

14. Clements JL Jr, Abernathy J, Weens HS : Corrugated mucosal pattern in the esophagus associated with progressive systemic sclerosis. Gastrointest Radiol 3:119-121, 1978

15. Clements JL Jr, Abernathy J, Weens HS: Atypical esophageal diverticula associated with progressive systemic sclerosis. Gastrointest Radiol 3:383-386, 1978

16. McLaughlin JS, Roig R, Woodruff MFA: Surgical treatment of strictures of the esophagus in patients with scleroderma. J Thorac Cardiovase Surg 61:641-645, 1971

17. Orringer MB, Dabich L, Zarafonetis CJD, Sloan H: Gastroesophageal reflux in esophageal scleroderma: diagnosis and implications. Ann Thorac Surg 22:120-130, 1976

18. Akiyama $\mathrm{H}$, Kugure $\mathrm{T}$, Iha $\mathrm{Y}$ : Esophageal reconstruction for stenosis due to diffuse scleroderma. Arch Surg $107: 470-472,1973$

19. Henderson RD, Pearson FG: Surgical management of esophageal scleroderma. $J$ Thorac Cardiovasc Surg $66: 686-692,1973$

20. Kilten L, Gottlieb JA: Scleroderma and carcinoma of the esophagus (letter). Lancet 2:707, 1971

21. Johnson BR, Monroe LS: Carcinoma of the esophagus de- veloping in progressive systemic sclerosis. Gastrointest Endosc 19:189-191, 1973

22. Whitaker JA, Bishop R: Scleroderma with carcinoma of the esophagus. Am J Gastroenterol 71:496-500, 1979

23. Ducan SC, Winkelman RK: Cancer and scleroderma. Arch Dermatol 115:950-955, 1979

24. Matzner MJ, Trachtman B, Mandelbaum RA: Co-existence of carcinoma and scleroderma of the esophagus. Am J Gastroenterol 39:31-42, 1963

25. Jonsson SN, Hauser JM: Scleroderma (progressive systemic sclerosis) associated with cancer of the lung. Brief review and report of a case. $N$ Engl J Med 255:413-416, 1956

26. Robbins $A H$, Vincent ME, Saini M, Schimmel EM: Revised radiologic concepts of the Barrett's esophagus. Gastrointest Radiol 3:377-381, 1978

27. Levine MS, Kressel HY, Caroline DF, Laufer I, Herlinger $\mathrm{H}$, Thompson JJ : Barrett's esophagus: reticular pattern of the mucosa. Radiology 147:663-667, 1983

28. Agha, FP: Radiologic diagnosis of Barrett's esophagus. Critical analysis of 65 cases. Gastrointest Radiol (in press)

29. Hawe A, Payne WS, Weiland LH, Fontana RS: Adenocarcinoma in the columnar epithelial lined lower (Barrett) oesophagus. Thorax 28:511-514, 1973

30. Naef AP, Savary M, Ozzello L: Columnar lined lower esophagus: an acquired lesion with malignant predisposition. J Thorac Cardiovasc Surg 70:826-835, 1975

31. Haggitt RC, Tryzelaar J, Ellis FH, Colcher H: Adenocarcinoma complicating columnar epithelium-lined (Barrett's) esophagus. Am J Clin Pathol 70:1-5, 1978

32. Thompson JJ, Zinsser KR, Enterline HT: Barrett's metaplasia and adenocarcinoma of the esophagus and gastroesophageal junction. Hum Pathol 14:42-61, 1983

33. Wesdarf ICE, Bartelsman J, Schipper MEI, Offerhaus J, Tytgat GN: Malignancy and premalignancy in Barrett's esophagus: a clinical-endoscopical and histological study. Acta Endoscop 11:317-322, 1981

34. Levine MS, Caroline DF, Thompson JJ, Kressel HY, Laufer I, Herlinger $\mathrm{H}$ : Adenocarcinoma of the esophagus: relationship to Barrett mucosa. Radiology 150:305-309, 1984

35. Agha FP: Barrett carcinoma of the esophagus. Clinical and radiographic analysis of 34 cases. AJR 145:41-46, 1985

Received: July 20, 1984; accepted: September 16, 1984 